\title{
Impact of Engineering Design-Focused Summer Academy Experience on In- terest Toward STEM Learning and Careers (Evaluation, Diversity)
}

\section{Dr. Kuldeep S. Rawat, Elizabeth City State University}

KULDEEP S. RAWAT is currently the Dean of Life, Physical Sciences, Mathematics and Technology and Director of Aviation Science program at Elizabeth City State University (ECSU).He has earned an M.S. in Computer Science, 2001, an M.S. in Computer Engineering, 2003; and, a Ph.D. in Computer Engineering, 2005, from the Center for Advanced Computer Studies (CACS) at University of Louisiana-Lafayette. He serves as the Site Director for NASA MUREP Aerospace Academy program at ECSU. His areas of interests include embedded systems design, cloud instrumentation, remote computing applications, UAS applications research, mobile robotics, and innovative uses of educational technologies. Dr. Rawat may be reached atksrawat@ecsu.edu.

\section{Ms. Robin Renee Mangham, Elizabeth City State University}

ROBIN R. MANGHAM is currently a lecturer in the Aviation Science Program at Elizabeth City State University (ECSU). She earned a Master of Aeronautical Science from Embry Riddle Aeronautical University in 2012. Areas of interest include education technology, human factors in aviation, and unmanned aircraft applications research. Ms. Mangham may be reached at rrmangham@ecsu.edu.

\section{Cmdr. Orestes Devino Gooden, Elizabeth City State University}

CDR. Orestes D. Gooden, retired US Navy Officer (Aviator) is an Assistant Professor at Elizabeth City State University. He has earned a B.S. in Geology from Virginia State University and M.A.S. in Aviation Operations from Embry-Riddle Aeronautical University. His areas of interests include: Human Factors in Aviation, Accident Investigation \& Safety, Corporate Aviation Operations, and Unmanned Aerial System (UAS). His passion for aviation education is noted as he is continuingly serving, educating and mentoring the next generation of aviators and aerospace industry students. He is certified by the FAA and qualified in both fixed wing, rotary wing and UAS aircraft.

\section{Mr. Elton L. Stone, Elizabeth City State University}

Elton L. Stone is currently a lecturer in the Aviation Science Program at Elizabeth City State University (ECSU). He earned a Master of Space Studies from American Military University in 2015. Areas of interest include aircraft design, aerodynamics, orbital mechanics, human factors in aviation, remote sensing and unmanned aircraft applications research. Mr. Stone may be reached at elstone@ecsu.edu. 


\title{
Impact of Engineering Design-Focused Summer Academy Experience on Interest Towards STEM Learning and Careers (Evaluation, Diversity)
}

\begin{abstract}
This paper presents implementation and evaluation of an engineering design-themed Summer Academy program geared towards exposing high school students, especially underrepresented and underserved groups, to science, technology, engineering, and mathematics (STEM) fields and careers. The goals of the engineering design activities were to (i) improve students' competence in science and engineering, (ii) nurture students' enthusiasm for science and engineering, and (iii) create student interest in research or other science and engineering-related careers. The program targeted rural counties surrounding project site and served eighty-one (81) students who received thirty-six (36) hours of handson STEM learning experience. Project evaluation data was gathered through Student Feedback Surveys, Dimensions of Success (DoS) Observation tool, pre/post topic selfefficacy, and survey student interviews. The results showed that engineering design activities had a positive impact on attitude towards STEM learning and careers. Integration of engineering design principles, student demographics and evaluation instruments and results are discussed in this paper.
\end{abstract}

\section{Introduction}

Engineering is a natural platform for the integration of science, technology, engineering, and mathematics (STEM) content into K-12 classrooms, while sparking creativity amongst young minds. Research around effective learning in K-12 classrooms demonstrates that an engineering approach to identifying and solving problems is valuable across all disciplines. Educators and administrators at all levels are recognizing the need to improve STEM education and introduce engineering design concepts before college. A National Academy of Engineers report, Engineering in K-12 Education: Understanding the Status and Improving the Prospects, suggests that the STEM disciplines not be treated as silos and that engineering might serve as a motivating context to integrate the four STEM disciplines [1].

Research has shown that students learn through experiences, and the earlier they are exposed to STEM-based hands-on learning experiences, the better. Engineering design, by its nature, is an inquiry-based pedagogical strategy that promotes learning across disciplines.

Engineering curricula introduces K-12 students to everyday applications of STEM fields that match their values and view of the world. The project's hands-on activities are designed to engage students in hands-on STEM experiences to improve their understanding of fundamental concepts in a way that capitalizes upon their design, visualization, creativity and teamwork skills and yearnings.

Incorporating mathematical and scientific fundamentals via engineering design-based methodology that infuses engineering habits of mind has proven to be a highly effective model for STEM education. The National Academy of Engineering found that engineering in K-12 education has the power to improve learning and student achievement in science and math, as well as develop student interest in, and preparedness for, the STEM workforce [1].

An increasing number of jobs at all levels require knowledge of mathematics and science. Several reports have linked K-12 science and math education to continued economic growth in the United States [2]. Unfortunately, there is a shortage of both interested and adequately 
prepared K-12 students, especially among minority youth and young women. There are significant gaps in achievement between student population groups: the black/white, Hispanic/white, and high-poverty/low-poverty gaps are often close to one standard deviation in size. The reasons are many, including: lack of authentic learning activities, inadequate K12 teacher preparation, especially in math and science content, poor alignment of K-12 and college curricula, and insufficient collaboration between K-12 and higher education institutions to smooth student transitions from high school to college [3]. These challenges, coupled with issues such as expectations gap and guidance gap become a major deterrent to improving achievement and attainment of postsecondary educational goals [4]. In fact, in all racial/ethnic groups, the low-performing students who need the most help in developing educational goals are the least likely to have received such help.

Gaps in science and math achievement for students, especially from underserved and rural communities must be closed, so more youth can reach their potential in achieving postsecondary educational goals. Research has shown that the out-of-school environmentafter school and summer-advances science and math knowledge and increases interest in postsecondary education and careers [5],[6]. These summer and/or out-of-school math and science focused programs combined with the $21^{\text {st }}$ century learning environment are required to close the opportunity gap that prevents underrepresented youth from reaching their full potential in meeting college readiness requirements [7].

The Next Generation Science Standards (NGSS), released in April 2013, were developed to help improve K-12 STEM education through actively engaging students in science and engineering practices while deepening their understanding of the core ideas and interrelationships in these fields over multiple years of exploration. These new academic standards at the state and national level call for integrating engineering design into the K-12 science curriculum. This is accomplished by raising engineering design to the same level as scientific inquiry. As a result, engineering design experience is gradually becoming a vital component of K-12 education, especially at the high school level. The process of initiating and completing an engineering design project requires students to engage both in analytical reasoning, active creation, and testing of solutions. One must ensure that engineering design projects are engaging for all students, particularly those from demographics that are underserved, underperforming, or underrepresented in the STEM fields. Well-crafted engineering design projects can increase students' interest in STEM and their self-efficacy in solving engineering problems.

The goal of these standards is to increase public understanding and appreciation of the role science and engineering play in everyday life. Because program curricula are aligned to the NGSS, this presents K-12 educators and schools with the opportunity to develop students' skills and knowledge in ways that help them succeed in today's increasingly-technological world. Studies have shown that rural students are less likely to attend college, have greater gaps between high school graduation and entering college, and are less likely to be continuously enrolled in college [8]. In addition, many rural students do not see the connection between their high school education and careers. Engineering-focused programs can help rural students aim high while providing real-world, experiential learning opportunities. These experiences can motivate students to engage in more rigorous coursework, envision pursuing postsecondary education, and prepare for high-demand careers.

Research indicates that hands-on, inquiry-based activities delivered in informal environments are key factors in helping to develop critical thinking skills and play a significant role in 
increasing students' interest and engagement in STEM and the likelihood that they will consider science and engineering-related occupations [9]. Several factors are associated with students' continued participation in STEM disciplines, and ultimately, their pursuit of STEM careers. A key factor is student interest in STEM.

\section{Program Description}

The engineering-focused STEM Academy project was a partnership between an institution of higher learning, school districts, private foundations, and other STEM enrichment programs. The program at Elizabeth City State University (ECSU) introduces groups traditionally underrepresented in STEM fields to careers in aerospace and aviation through a balanced mix of theory, hands-on activities, field trips, and guest seminars/lectures. Hands-on learning activities integrated modern educational technology tools and inquiry-based learning to reinforce science and mathematical concepts required to enter STEM careers. Students learned about potential college and career opportunities that exist in these fields and why a background in advanced science and mathematics is crucial to achieve these careers.

The program offered out-of-school-time hands-on STEM learning experience for students from middle and high school grade levels. The project target area comprised of 21 counties surrounding ECSU. This region has long suffered the effects of poverty and has lacked the opportunities for most students to encounter the $21^{\text {st }}$ century workplace that is readily accessible in more urban areas of the state. However, with recent growth in the manufacturing, biotechnology, aviation and aerospace industry in the region, there now exists the potential to link K-12 STEM education to these industries. Annually, over 600 students from middle and high schools participate in activities that are delivered through Friday Academy, Saturday Academy, and Summer Academy.

In this paper, Summer Academy component of the year-round program is discussed. As part of the Summer Academy, eighty-one (81) high school students participated in two, weeklong residential summer academies, engaged in thirty-six (36) hours of an engineering design project activity that culminated into a highly exuberant competition. The goals of the engineering design activities were to (i) improve students' competence in science and engineering, (ii) nurture students' enthusiasm for science and engineering, and (iii) create student interest in research or other science and engineering-related careers.

The three key components of the STEM Academy program were: (i) Curriculum Enhancement Activities (CEA) - Hands-on, inquiry-based K-12 STEM curricula (ii) Aerospace Education Laboratory (AEL) (iii) Family Connection (FC) - parental/guardian involvement and outreach.

The program team developed curriculum enhancement activities (CEAs) by adopting a wellestablished NASA STEM curriculum with problem-based learning at its core and integrated 3D printing technology, sensor-based measurement systems, and mini Unmanned Aerial Vehicle (UAV) design activities to enhance authentic and experiential learning experiences. Integration of these technologies added an additional dimension to the value of scientific inquiry and shows how to apply scientific knowledge, procedures and mathematics to solve real problems and improve the world we live in. The curriculum supported the Next Generation Science Standards and contained a strong emphasis on math and science literacy for the $21^{\text {st }}$ century learners. 
Hands-on learning was provided through the AEL, a state-of-the-art laboratory that features collaborative learning environment and equipped with hardware and software to support curriculum enhancement activities. The hands-on activities included 3D Printing, Data/sensor acquisition, mobile Robotics programming, Wind and Solar Energy, Computer Programming (Raspberry PI/Arduino), Wind Tunnel experiments, Science Experiments and more, ready to inspire the next generation of STEM professionals. Wherever appropriate, instruction included covering relevant mathematics and science concepts needed for the hands-on activity. Activities also included demonstration to reinforce STEM topics taught during the week at respective schools where participants came from.

The FC was an interactive forum that provides STEM education and parenting or caregiving information to any supportive adult role model(s) who interacts with the students. The FP involved parents/families as a partner with the ECSU site in the planning, design and implementation of the NASA inspired curriculum. Parents/Guardians were provided STEM skills to engage them in supporting their children's learning at home.

\section{Program Goals and Activities}

The Summer Academy program engaged students through hands-on learning activities, integrated modern educational technology tools and inquiry-based learning to reinforce science and mathematical concepts required to enter STEM careers, especially engineering fields. Students learned about potential college and career opportunities that exist in these fields and why a background in advanced science and mathematics is crucial to achieve these careers. However, a balance must be met for providing a rigorous academic environment for the students while allowing them to enjoy the program's activities so that they will remember the experience positively and perhaps consider engineering-related college programs and eventually pursue such careers in these fields. This challenge was met by supplementing classroom instruction with exposure to hands-on experiments, engineering design challenge, and field trips that submersed the students in a wide variety of topics and experiences in STEM.

The three program goals and the summary of corresponding program activities to meet those goals are presented next.

\section{Goal 1: Nurturing students' enthusiasm for STEM}

The activities were aimed to nurture the aerospace/aviation academy students' enthusiasm for STEM; all the sessions provided interactive components through virtual simulation that sought to excite the participants about the scientific and engineering applications and engage students in hands-on activities that were applicable to the real world. Prior to working on the engineering design project, the students participated in a field trip to a large-scale wind farm owned by Amazon, located close to ECSU campus. This trip helped students see how the topics they are learning, are relevant in the real world. Learner-centered experiences in a realworld context greatly increased the students' engagement, enthusiasm, and achievement. Later, in the classroom students reviewed animations, videos, and other learning material on wind energy and wind turbine information available on the National Renewable Energy Laboratory (NREL) website. This was followed by a brainstorming session and technical discussion on wind turbines. Daily log entries of project activities and student reflections were recorded in an engineering notebook. 
Mentors were available to assist project teams when needed. Being part of a competition at the end of the project was instrumental in keeping student enthusiasm for activity at a higher level.

\section{Goal 2: Improving students' competence in STEM}

Curriculum enhancement activities (CEAs) that meet NGSS and NC Standards for Science and Math were at the core of improving students' competence in science. Students in high school grade levels were engaged in engineering design projects as the theme for Summer Academy. Other learning activities including sensor-based science experiments, electronics, microcontroller programming, hands-on demonstrations, and review of science and mathematical concepts relevant to the topic. During the Summer Academy-Residential high school students $\left(9^{\text {th }}-12^{\text {th }}\right.$ grade levels) were introduced to the engineering design process as shown in Figure 1 in the beginning of the session.

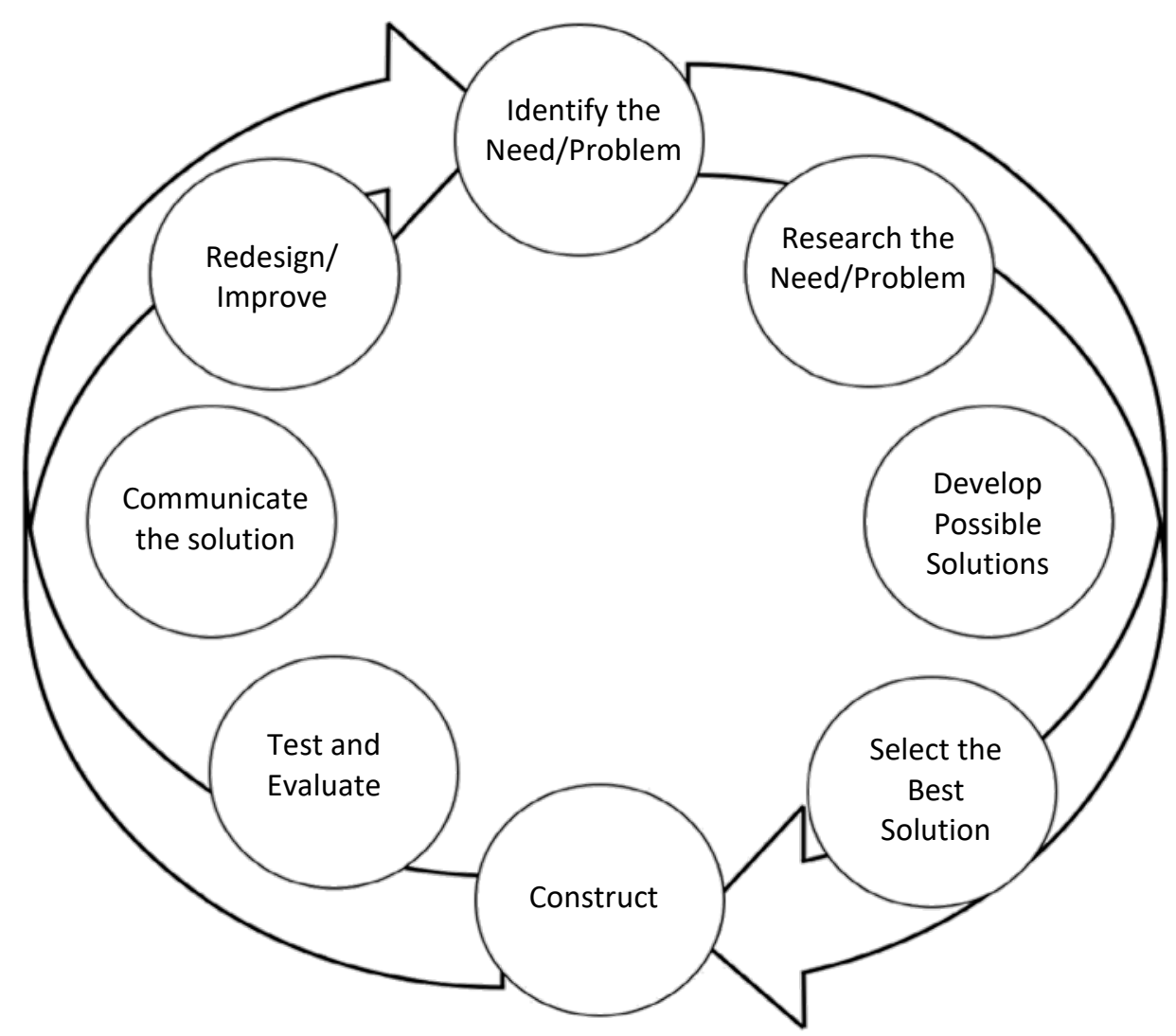

Figure 1: Engineering Design Process Cycle

Goal 3: Interesting students in research or other STEM-related careers

Students were encouraged to engage in self-directed inquiry when refining their project designs to meet the specifications. Students maintained record of their incremental designs and changes made to improve the output. All activities were recorded in the engineering notebooks. The participants also had countless opportunities to meet scientists, engineers, and other persons from STEM-related fields during the program.

Program activities were critical in achieving program goals of advancing STEM literacy, educating students utilizing a curriculum that meets national STEM standards, and inspire 
and prepare a more diverse student population to pursue college and careers in STEM-related disciplines. Program activities included CEAs, field trips, guest speakers, laboratory visits, mentorship, interactions with professionals, team projects, an engineering design competition, and other confidence building exercises. Summer Academy program activities and sessions are summarized in Table 1.

Table 1: Summer Program Activities

\begin{tabular}{|c|c|c|c|c|}
\hline Sessions & Duration & $\begin{array}{c}\text { \# of } \\
\text { Sessions }\end{array}$ & $\begin{array}{l}\text { Grade } \\
\text { Level }\end{array}$ & Activities/Topics \\
\hline $\begin{array}{l}\text { Summer } \\
\text { Academy - } \\
\text { Residential }\end{array}$ & $\begin{array}{l}1 \text { week } \\
\text { (7-8 hours/day) }\end{array}$ & 2 camps & \multirow{3}{*}{$\begin{array}{l}\text { High } \\
\text { School } \\
\text { only } \\
\text { (9-12 } \\
\text { grade) }\end{array}$} & $\begin{array}{l}\text { Engineering Design Principle, Wind } \\
\text { Turbine Design Challenge, Electronics, } \\
\text { Sensor/Data Logging, Arduino } \\
\text { Microcontrollers, Renewable Energy, } \\
\text { and Computer Programming }\end{array}$ \\
\hline Field Trip & & 2-3 trips & & $\begin{array}{l}\text { Virginia Air and Space Museum, } \\
\text { Amazon Wind Energy Farm, US Coast } \\
\text { Guard Air Station }\end{array}$ \\
\hline Guest Speakers & 1-2 hours & $\begin{array}{l}2 \\
\text { speakers }\end{array}$ & & $\begin{array}{l}\text { Careers and Opportunities in Science and } \\
\text { Engineering, Significance of STEM, } \\
\text { Preparing for College and Beyond }\end{array}$ \\
\hline
\end{tabular}

\section{Program Evaluation and Results}

\section{Student Participation}

A total of eighty-one (81) students participated in the Residential Summer Academy Program. Two summer academies, each week-long were offered during the Summer of 2017 on ECSU campus. The outreach and intervention initiative in this project targeted high school students $\left(9^{\text {th }}-12^{\text {th }}\right.$ grade level $)$, especially from underrepresented backgrounds within the 21 county school districts, one of the most economically disadvantaged, underserved, and rural communities in the state and nation.

The program offering was marketed to all the schools in the targeted area. Marketing materials created in the program development stage (Brochures, Flyers, Emails and Web links) were distributed to each district office and school in the targeted area. Additionally, project team members contacted each school superintendent directly, distributed applications to guidance counselors, and were available for questions.

Table 2 indicates the percentage of participants by grade level.

Table 2: Percent of Participants by Grade Level
\begin{tabular}{|c|c|}
\hline Grade Level & $\%$ of total Participants \\
\hline & \\
\hline Grade Level 9 & $25.92 \%$ \\
\hline Grade Level 10 & $25.92 \%$ \\
\hline Grade Level 11 & $24.69 \%$ \\
\hline Grade Level 12 & $23.45 \%$ \\
\hline
\end{tabular}

The participants consisted of 40.74\% (33) female students and 59.26\% (48) male students. 
The graph in Figure 2 shows the program participants by ethnicity.

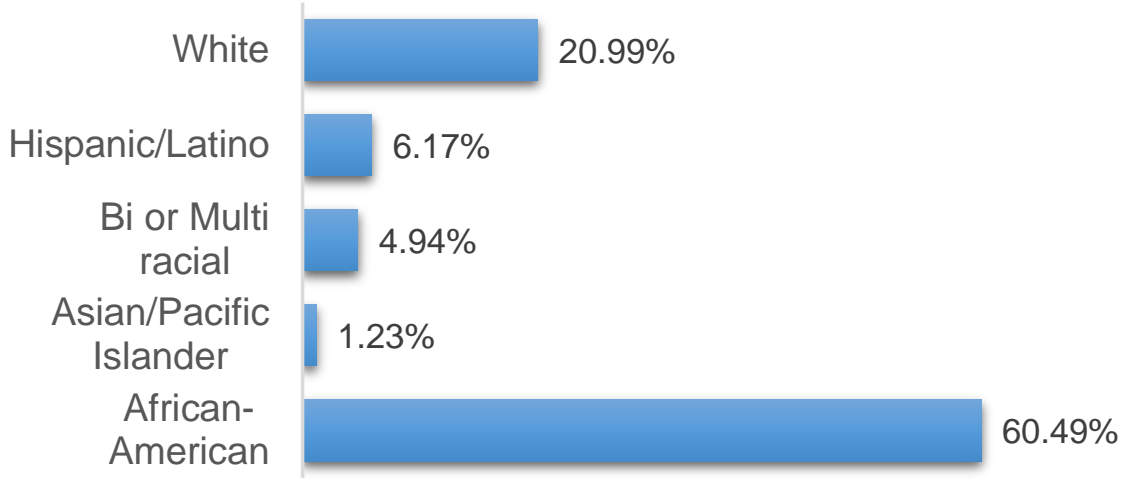

Figure 2: Program Participants by Ethnicity

As seen from Figure 2, the program was successful in recruiting over 65\% students from underrepresented groups.

\section{Evaluation Instruments and Results}

Data collection instruments that were used for conducting evaluation included a Student Feedback Survey, a pre/post topic self-efficacy assessment survey, Dimensions of Success (DoS) Observation tool, student interviews. The participating students were administered evaluation instrument only after all necessary release of privacy documents as prescribed by ECSU Institutional Review Board (IRB) procedures are completed. The ECSU project team has received IRB approval via an expedited review process.

A brief description of evaluation instruments and corresponding results are as follows:

Student Feedback Survey: This survey was completed by student participants after completing at least 36hrs of hands-on learning. The survey was used to assess the overall interest towards pursuing STEM degree and careers. ECSU Summer Academy program adopted (and modified) a post only survey originally developed by The Program Evaluation Group for Science enrichment programs. The original instrument has been used to evaluate several K-12 science enrichment programs for over fifteen (15) years.

The questions (Q1a-g) are listed below:

a. This program helped me better understand STEM areas.

b. Because of this program, I feel better about being able to learn STEM topics.

c. I learned some things in this program that I can use in class at school.

d. Because of this program, I think I am more aware of the importance of STEM in everyday living.

e. I tell my family or friends about the things we do in this program.

f. Because of this program, I am more excited about STEM fields.

g. Because of this program, I think I have a better understanding of what STEM Professionals do.

Students responded to each question on a five-point Likert scale of: Strongly Disagree; Disagree; I don't know; Agree; Strongly Agree. The bar graph in Figure 3 shows the 
response results to these survey questions.

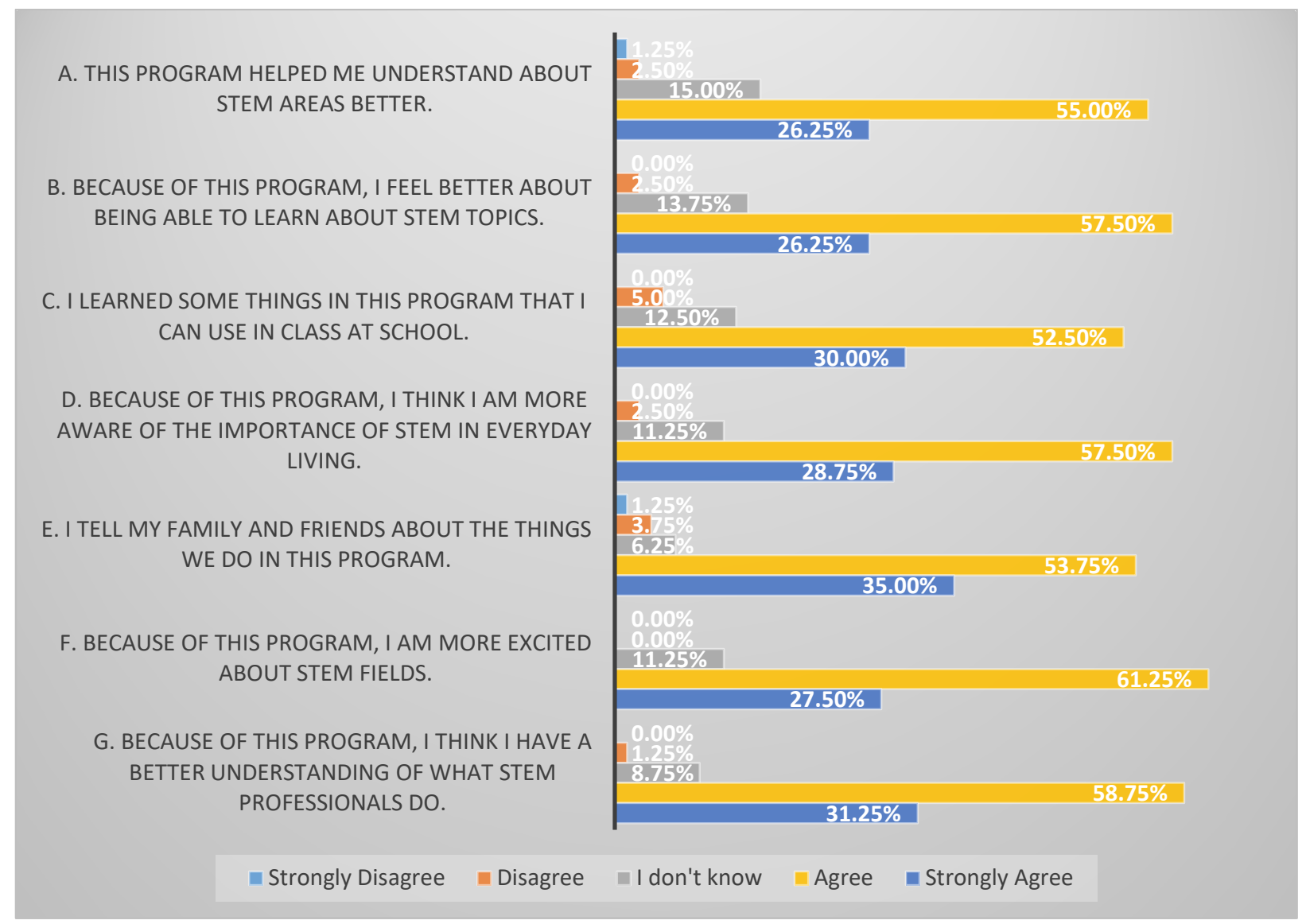

Figure 3: Percentage of Respondents to the Student Feedback Survey Questions Q1a-g

Q2. How would you describe your interest in STEM before this program?

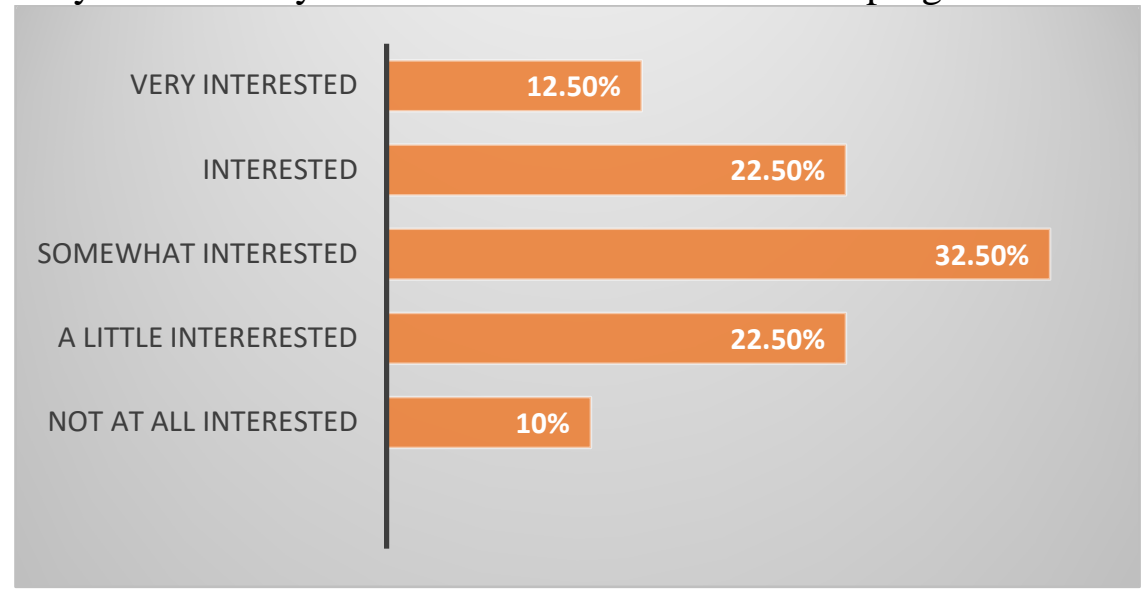

Figure 4: Participants prior interest in STEM 
Q3. Has this program changed your feelings about STEM learning?

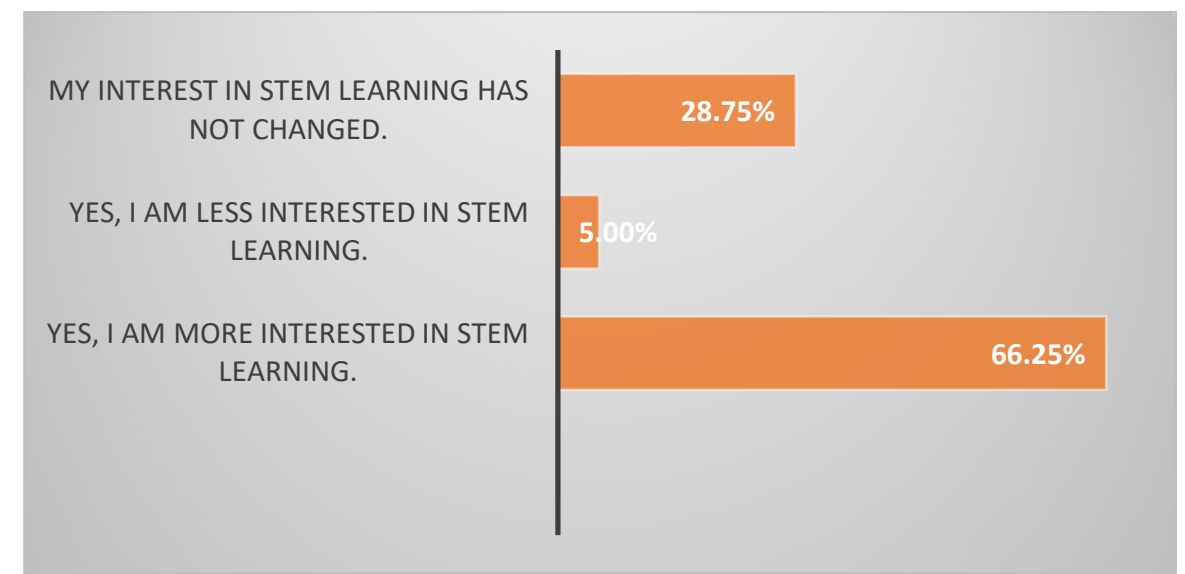

Figure 5: Participants change in interest towards STEM learning

Q4. Has this program encouraged you to think about taking more STEM classes in the future?

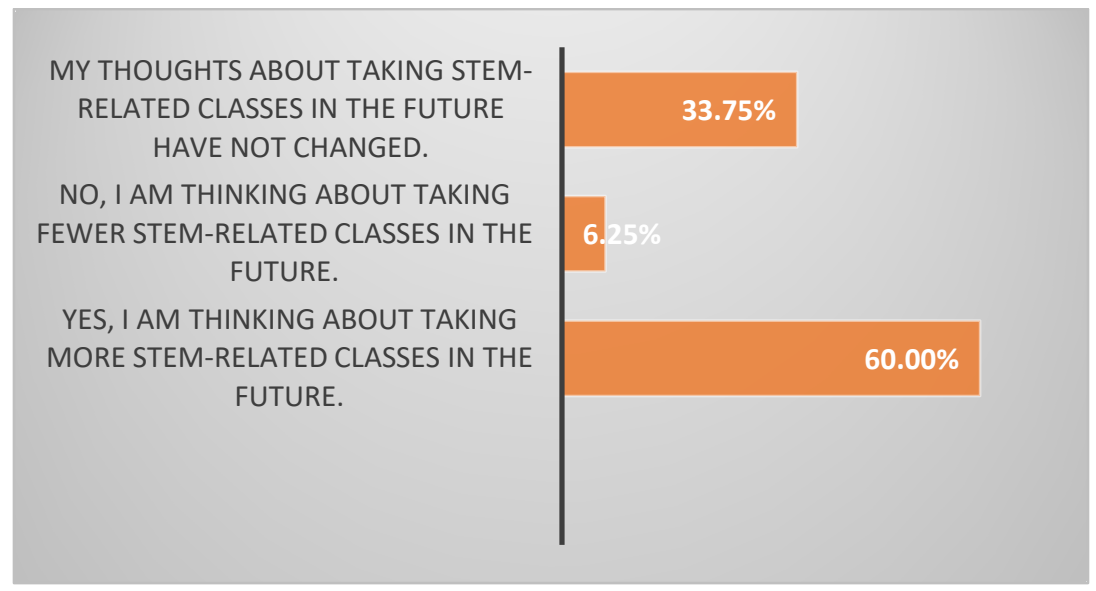

Figure 6: Participants change in interest towards taking STEM classes in future

Q5. Has this activity encouraged you to think more about getting a job in a STEM-related career?

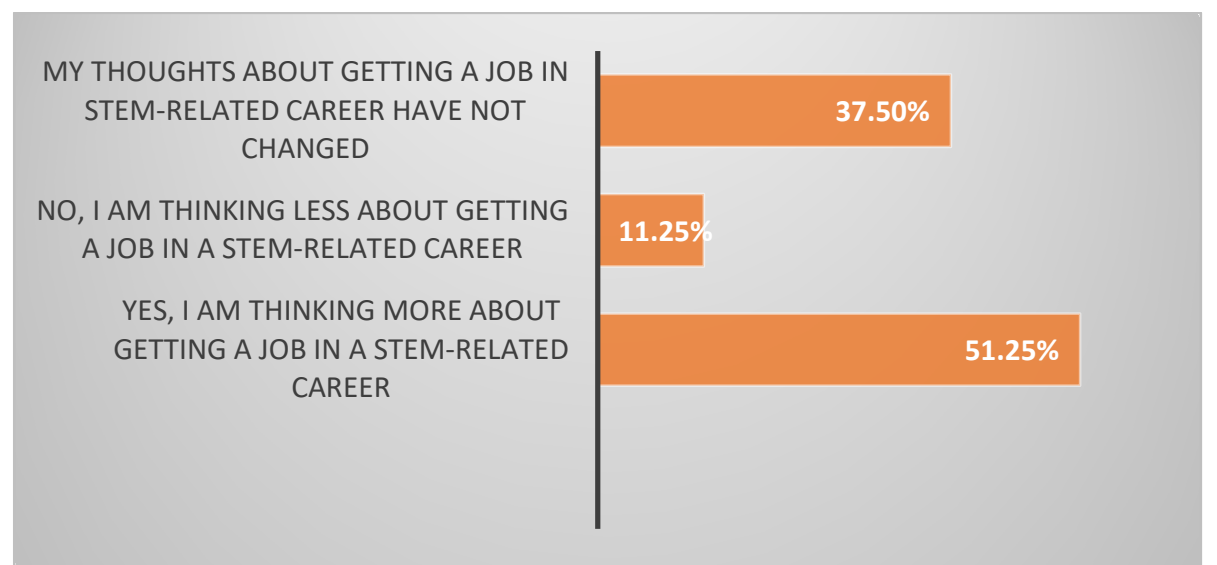

Figure 7: Participants change in interest towards pursuing STEM-related career 
Topic Pre/Post-Assessment Self-Efficacy Survey: Students in the two residential summer academies were given a pre- and post-assessment survey to determine the level of impact the program's hands-on project activities had on student learning. Engineering design process was the theme used for the academies, where students learned the engineering design process and applied it in designing, building, and testing a functional wind turbine. Pre/post surveys assessed students' self-reported confidence in their ability to apply engineering design to a project. Student responses were averaged and an independent two-sample t-test was conducted. The following five questions were analyzed from the two residential camps:

1. I am able to apply the Engineering Design Process in a project.

2. I am able to define the role of individual components of a wind turbine.

3. I am able to explain the working of a wind turbine.

4. I am able to design, test, and troubleshoot a wind energy generation system.

5. I am able to use a signal acquisition device to test and measure wind turbine efficiency.

Students responded on a 3-point Likert Scale to each of the questions with (1) for "No", (2) for "Somewhat", or (3) for "Yes." It was hypothesized that following the hands-on project activities, more students would feel confident in their engineering design abilities. The null hypothesis was the weeklong program activity would cause no change in the students' selfefficacy. An independent two-sample t-test was conducted to compare the average for each response in the Pre and Post assessment questionnaire.

Table 3: Summer Academy Group 1 and 2 Independent t-Test Results.

\begin{tabular}{r|rrrr} 
Descriptive Statistics & Summer Academy & Group 1 & \multicolumn{2}{c}{ Summer Academy Group 2} \\
\hline & Pre & Post & Pre & \multicolumn{1}{c}{ Post } \\
Mean & $\mathbf{1 . 6 5 3 6 6}$ & $\mathbf{2 . 6 7 8 0 5}$ & $\mathbf{1 . 4 8}$ & $\mathbf{2 . 5 2 1 9 5}$ \\
Standard Error & 0.07225 & 0.04411 & 0.05675 & 0.06839 \\
Median & $\mathbf{1 . 6}$ & $\mathbf{2 . 8}$ & $\mathbf{1 . 4}$ & $\mathbf{2 . 6}$ \\
Mode & 1.6 & 3 & 1.2 & 2.8 \\
Standard Deviation & $\mathbf{0 . 4 6 2 6 5}$ & $\mathbf{0 . 2 8 2 4 1}$ & $\mathbf{0 . 3 5 8 9 2}$ & $\mathbf{0 . 4 3 7 9}$ \\
Sample Variance & 0.21405 & 0.07976 & 0.12882 & 0.19176 \\
Kurtosis & -0.01267 & -0.60369 & -0.25661 & -0.5739 \\
Skewness & 0.81513 & -0.57698 & 0.64783 & -0.73383 \\
Range & 1.8 & 1 & 1.4 & 1.4 \\
Minimum & 1 & 2 & 1 & 1.6 \\
Maximum & 2.8 & 3 & 2.4 & 3 \\
Count & 41 & 41 & 40 & 40
\end{tabular}

Two-Sample t-Test Summer Academy Group 1 Summer Academy Group 2

\begin{tabular}{r|rrrr}
\hline & \multicolumn{1}{|c}{ Pre } & Post & Pre & \multicolumn{1}{c}{ Post } \\
Mean & 1.65366 & 2.67805 & 1.48 & 2.52195 \\
Variance & 0.21405 & 0.07976 & 0.12882 & 0.19176 \\
Observations & 41 & 41 & 40 & 40 \\
Hypothesized & 0 & & 0 & \\
Mean Difference & & & 77
\end{tabular}




\begin{tabular}{r|rr} 
t Stat & $-\mathbf{1 2 . 1 0 1 2}$ & -11.7247 \\
$P(T<=t)$ two-tail & $2.1 \mathrm{E}-18$ & $\mathbf{8 . 4 E - 1 9}$ \\
$t$ Critical two-tail & 1.99656 & 1.99125
\end{tabular}

The two-sample independent t-test with a .05 confidence level was used and there was a significant difference in the mean scores; Summer Academy 1 pre-assessment mean was 1.65 and a mean of 2.68 on the post-assessment. Summer Academy 2 pre-assessment mean was of 1.48 and mean on post-assessment was 2.52 suggest. Increase in mean between pre- and postassessments indicate that the students felt more confident in their abilities to apply engineering design process in a project. Two-sample t-test helped to determine if this increase in mean is significant. The calculated p-values of 2.06406E-18 for Summer Academy 1 and 8.37864E-19 for Summer Academy 2 fall well below the $\mathrm{p}<0.05$ and thus indicates strong evidence of higher self-reported confidence following the program activities. Tables 18 depicts the two-sample t-test on each summer academy group.

For Summer Academy Group 1, the critical t-value is 1. 996564419 and |t-value| is 12.1011839. So, the |t-value| is greater than the critical t-value, which indicates the difference between the two sets is significant. This is further confirmed by the fact that two-tailed Pvalue is 2.06406E-18; this is extremely small (much less than 0.05).

Dimension of Success (DoS) Observation Tool: Program quality was evaluated using the Program in Education, Afterschool \& Resiliency's (PEAR) Dimensions of Success (DoS) observation tool. The DoS is an observation tool that focuses on 12 dimensions of quality in STEM out-of-school programs, which are grouped into four broader domains. During each observation, the selected dimensions were rated using a four-level rubric representing increasing quality, where a rating of " 1 " indicates that evidence is absent, " 2 " indicates there is inconsistent evidence, " 3 " indicates there is reasonable evidence, and " 4 " indicates there is compelling evidence. According to the developers of the DoS, ratings of three or four on a dimension are desirable.

A total of four observations were conducted by a certified DoS observer during the program. Observation days and times were random to avoid bias from a particular lesson, instructor, or group of students. For the Summer Academy program focus was on improving student engagement and STEM knowledge. Table 4 depicts the average DoS score and the corresponding range for the observations. Average scores were equal to or greater than three in all categories. Scores were highest (3.5 or higher) in three categories, including Purposeful Activities, STEM Content Learning, and Inquiry.

Table 4: Average DoS Scores of Observations on a 4-point scale.

\begin{tabular}{|l|l|c|c|}
\hline \multicolumn{1}{|c|}{ DoS Domain } & \multicolumn{1}{|c|}{ DoS Category } & \multicolumn{2}{c|}{$\begin{array}{c}\text { DoS Scores (n=4) } \\
\text { Average }\end{array}$} \\
\hline Activity Engagement & Participation & 3.25 & $2-4$ \\
& Purposeful Activities & 3.75 & $3-4$ \\
& Engagement with STEM & 3.25 & $3-4$ \\
\hline STEM Knowledge and & STEM Content Learning & 3.5 & $3-4$ \\
Practices & Inquiry & 3.5 & $3-4$ \\
& Reflection & 3.25 & $2-4$ \\
\hline
\end{tabular}

The classroom used at ECSU allowed informal group projects and students were arranged around tables that allowed interaction and use of all provided technology. Students were 
encouraged to work within their own and among other teams during all projects. Strengths noted during these observations included Engagement with STEM, Inquiry, and STEM Content Learning.

Student Interviews: Semi-structured and conducted informally during high school summer camps during various hands-on project activities. Interviews were conducted by an independent evaluator. Five students were selected from the participating students during residential summer camp for interview. The student interview questions and responses are summarized as follows:

1. What made you decide to attend this camp?

-My father found the camp and said, "Why not?" He knew I had an interest in

Engineering.

-My dad heard about it and said I should go.

-I wanted to broaden my knowledge on the topics and careers.

-My friend attended a similar program last year and recommended it to me. I am interested in Engineering.

-I wanted to see more things in advanced technology, such as ATC and Flight

Simulators.

2. Have you always had an interest in STEM subjects and/or STEM careers?

-Yes/Yes. Biomedical

-Yes/Yes. Electrical or Computer Engineering

$-\mathrm{No} / \mathrm{No}$.

-Yes/Yes. I have always loved math.

-Yes/Yes. Aerospace-Aviation

3. What aspect of the camp do you think is most exciting or interesting? Why?

- "Building wind turbine and meeting new people. I also enjoyed programming robot motor and ping sensor."

- "Flying, many people haven't done it. I have a couple of times, but it is always cool to go up".

- "Museum visits...Wind Turbine project...meeting all the different people such as the instructors, guest speakers, etc."

- "Getting to go on all the tours such as the Air and Space Museum. Big Wind Farm visit was good too. The mentors are great."

- "Field Trips! Other camps I've went were just classroom work."

4. Has this camp improved your knowledge of STEM topics and/or increased interest in a STEM degree/career?

-Yes, Increased my interest in Aerospace Engineering.

-Yes, it improved from talking to instructors and others on field trips.

-Yes/Yes. It was really fun here. Hope you do this camp again next year so more kids can learn about aerospace, robotics, etc.

-Yes, 100\%. I have learned so much more here than even in my classes at school.

-Yes, this gives me more options when I go to college, especially aviation. 


\section{Conclusion}

In this paper, implementation and evaluation of an engineering-focused summer academy program component of a year-round K-12 outreach program conducted on Elizabeth City State University campus was discussed. The goal of this program is to improve students' competence in science and engineering, create students' enthusiasm for science and engineering, and encourage and motivate them to pursue science and engineering-related degree/careers. A total of eighty-one students participated through in the Summer Academies. Program was successful in recruiting minority students, where over $60 \%$ of students were African-American. STEM topics included engineering design project, sensors and data logging, basic electronic circuits, renewable energy (solar and wind), and Arduino microcontrollers. Program team used multiple instruments to assess the impact of program. Evaluation data shows that 36-40 hours of hands-on engineering design project and other STEM activities resulted in significant gains in interest in learning Science and Engineering topics. The informal setting and activities were conducive for effective learning, increasing student engagement and increasing STEM content knowledge, evident from DoS observations scores. Guest speakers and field trips completed the hands-on learning activities offered in an informal learning environment. 


\section{References}

[1] Katehi, L., Pearson, G., and Feder, M. (2009). Engineering in K-12 Education: Understanding the Status and Improving the Prospects, Committee on K-12 Engineering Education; National Academy of Engineering and National Research Council.

[2] President's Council of Advisors on Science and Technology (2012). Engage to Excel: Producing One Million Additional College Graduates with Degrees in Science, Technology, Engineering, and Mathematic. Retrieved from www. whitehouse.gov/sites/default/files/microsites/ostp/pcast-engage-toexcel-final_feb.pdf.

[3] ACT. (2014). The Condition of STEM 2013 - National. Retrieved on May 25, 2015 from ACT: http://www.act.org/stemcondition/13/pdf/National-STEM-Report-2013.pdf.

[4] Afterschool Alliance, (2012) Afterschool essentials: Research and polling. Retrieve from ` http://www.afterschoolalliance.org/documents/2012/Essentials_4_20_12_FINAL.pdf.

[5] Conley, D. T. (2007). Redefining college readiness, Volume 3. Eugene, OR: Educational Policy Improvement Center.

[6] BGCA. (2014). Advancing Underrepresented Youth in STEM During Out-of-School Time, STEM Great Think, May 2014, Redwood City, CA.

[7] Gardner, M., Roth, J. L., \& Brooks-Gunn, J. (2009). Can after-school programs help level the academic playing field for disadvantaged youth? Equity Matters: Research Review No. 4. Retrieved from: http://www.equitycampaign.org/i/a/document/11242_After-school_report 10-7-09_web.pdf.

[8] Byun, S-Y., Irvin, M. J., \& Meese, J. L. (2015). Rural-nonrural differences in college attendance patterns. Peabody Journal of Education, 90(2), 263-279.

[9] Minner, D., Levy, A. J., \& Century, J. (2010). Inquiry-based science instruction-What is it and does it matter? Results from a research synthesis. Journal of Research in Science Teaching, 47(4), 474-496.

\section{Acknowledgement}

This project was supported by the National Aeronautics and Space Administration (NASA

Cooperative Agreement\# 80NSSC18M0141 and the Burroughs Wellcome Fund Grant ID 1016566). 